\title{
ANÁLISE MICROBIOLÓGICA DE CACHORRO QUENTE COMERCIALIZADO EM DIFERENTES ESTABELECIMENTOS EM UM MUNÍCIPIO DA REGIÃO OESTE DO ESTADO DO PARANÁ
}

\section{MICROBIOLOGICAL ANALYSIS OF HOT DOGS MARKETED IN DIFFERENT ESTABLISHMENTS IN A MUNICIPALITY OF THE WEST REGION OF THE STATE OF PARANÁ}

\author{
Hiorana Pelentier de Lima ${ }^{1}$, Sóstenez Alexandre Vessaro da Silva ${ }^{{ }^{*}}$, Laís Dayane \\ Weber ${ }^{3}$. \\ ${ }^{1}$ Bióloga, Centro Universitário da Fundação Asssis Gurgacz (FAG). ${ }^{2}$ Biólogo Doutor em Biologia das \\ interações Orgâncias, Docente do Curso de Nutrição do Centro Universitário da Fundação Asssis \\ Gurgacz (FAG). ${ }^{3}$ Bióloga. Mestre em Conservação e Manejo de Recursos Docente do curso de \\ Ciências Biológicas do Centro Universitário da Fundação Assis Gurgacz (FAG). \\ Autor correspondente: sostenezalexandre@hotmail.com, https://orcid.org/0000-0002-2114-7277
}

\section{RESUMO}

O comércio de alimentos preparados e comercializados por vendedores ambulantes possui um aumento significativo no Brasil devido ao crescimento da população mundial e dos processos de urbanização. Com o passar do tempo as pessoas estão tendo que se alimentar com muito mais frequência em vias públicas, pois estão localizadas em locais mais próximas dos seus trabalhos e estudo. Essas mudanças de hábitos, podem colocar a saúde do consumidor em risco devido às doenças transmitidas por alimentos (DTA'S). O presente estudo teve como objetivo avaliar a qualidade microbiológica de cachorros-quentes comercializados em diferentes estabelecimentos em um município da região oeste do estado do Paraná, para a verificação de possível presença de Salmonella spp., mesófilos aeróbios, Staphylococcus aureus, e os coliformes totais e fecais. Foram avaliadas 5 amostras de cachorros quentes de diferentes estabelecimentos. Das amostras analisadas, $40 \%$ estavam em desacordo com os padrões estabelecidos para as contagens de aeróbios mesófilos, $100 \%$ para coliformes totais, $40 \%$ para coliformes Termotolerantes, $0 \%$ para Staphylococcus aureus, e 60\% para Salmonella spp.. Assim a análise de coliformes totais sugere que há necessidade de efetuar uma implantação das boas práticas de produção eficiente nos estabelecimentos avaliados, além de uma maior fiscalização por parte da vigilância sanitária do município.

Palavras-chave: Micro-organismos, alimentos, saúde pública, doenças.

\section{ABSTRACT}

The food trade prepared and marketed by street vendors has a significant increase in Brazil, due to the growth of the world population and the processes of urbanization as over time, people are having to feed much more frequently in public roads, which are closer to their work and places of study. However, these habit changes can put the health of the consumer at risk due to foodborne illness (DTA'S). The present study aimed to evaluate the microbiological quality of hot dogs marketed in different establishments in a municipality in the western region of the state of Paraná, to verify the possible presence of salmonella spp., Aerobic mesophiles, Staphylococcus 
aureus, and total coliforms and fecal. Five hot dogs from different establishments were evaluated. Of the samples analyzed, $40 \%$ were in disagreement with the standards established for mesophilic aerobic counts, $100 \%$ for total coliforms, $40 \%$ for thermotolerant coliforms, $0 \%$ for Staphylococcus aureus, and 60\% for Salmonella spp. Thus, coliform analysis suggests that there is a need to implement good practices of efficient production in the evaluated establishments, in addition to a greater supervision by the sanitary surveillance of the municipality.

Keywords: Microorganisms, food, public health, disease.

\section{INTRODUÇÃO}

Os micro-organismos estão presentes em praticamente todos os lugares, muitos são considerados patogênicos por causarem malefícios desencadeando diversas doenças. Esses seres vivos eram totalmente desconhecidos há alguns séculos e hoje são responsáveis por várias infecções e contaminações alimentares que levam muitas pessoas à morte (CARVALHO, 2016).

A alimentação é motivo de preocupação para vários países e setores relacionados à saúde pública, que tem como desafio diário a adequação e a produção de alimentos para o consumo da população, a fim de eliminar a contaminação dos alimentos por agentes biológicos e proporcionar para a população mundial alimentos de ótima qualidade (PARISSENTI et al., 2013).

O aumento significativo da população mundial, o processo de urbanização desordenado e a necessidade de produção de alimentos em grande escala são os principais fatores que incitam a ocorrência de Doenças Transmitidas por Alimento (DTA), pois com o passar do tempo as pessoas estão tendo que se alimentar com maior frequência em vias públicas, sem se importar com a qualidade do produto que estão consumindo (MS, 2010).

A fácil multiplicação dos micro-organismos patogênicos, não patogênicos e algumas práticas incorretas na manipulação destes alimentos faz com que haja um número significativo de possíveis ocorrências das DTA's, causando infecções ou intoxicações que podem afetar apenas uma pessoa de forma leve ou toda uma população, causando um surto que pode levar pessoas à morte. Devido a isto é de extrema importância conhecer os micro-organismos causadores de doenças e tentar combatê-los (OLIVEIRA et al., 2010).

O conhecimento dos pontos positivos e negativos que os micro-organismos causam aos seres vivos e a constante busca por respostas de todas as áreas que envolvem a microbiologia tornaram possível a descoberta da microbiologia de alimentos. A realização das análises que a microbiologia de alimentos faz, é obrigatória nas indústrias alimentícias, para reduzir ao mínimo possível a contaminação de alimentos evitando, assim, prejuízos para as indústrias e, consequentemente, evitar contaminações graves à população (EVANGELISTA, 2008).

Cada micro-organismo encontrado nos alimentos é responsável por um tipo de contaminação, podendo essa ser grave ou moderada. As indústrias e os comércios que produzem e vendem estes produtos, devem seguir práticas de higiene para evitar contaminações das matérias-primas e do produto (ANDRADE, 2008).

O processo de higienização nas indústrias é realizado por etapas, fazendo a limpeza de sanitização de cada máquina, superfície, manipuladores, utensílios e até mesmo do ambiente que a matéria-prima vai passar durante o processo de produção. As boas práticas de fabricação e armazenamento são de extrema importância para 
evitar a proliferação destes micro-organismos, proporcionando ao consumidor final um produto de ótima qualidade (MACHADO et al., 2015).

As análises microbiológicas de alimentos são importantes devido à fácil transmissão destes micro-organismos, sejam eles patogênicos ou não. Os microorganismos encontrados em produtos que podem causar algum tipo de problema para os humanos são: os coliformes totais e termotolerantes, que indicam a presença de resíduos orgânicos que podem causar infecções aos seres humanos por meio dos alimentos; com relação à Salmonella spp. a contaminação ocorre de maneira direta mediante consumo de leite, carnes, e outros alimentos e de maneira indireta por via de fezes humanas, de animais contaminados e de água poluída, ela se instala no intestino, e pode provocar septicemia, meningites e endocardites. Staphylococcus aureus é uma bactéria do grupo dos cocos gram-positivos, frequentemente encontrada na pele e nas fossas nasais de pessoas saudáveis. É considerado um dos tipos mais frequentes de intoxicação alimentar. Se ingerido em quantidades acima do permitido pela resolução RDC nำ12, pode causar náuseas, vômitos e diarreia. O grupo dos Mesófilos é um dos mais importantes para avaliar a qualidade do produto que chega ao consumidor final, ele sugere a presença de bactérias patogênicas presentes nos alimentos derivados de carne (EVANGELISTA, 2008; LIMA et al., 2008; FERREIRA et al., 2014; CARVALHO, 2016;).

Desta forma, o presente trabalho tem como objetivo avaliar a presença de micro-organismos patogênicos a humanos em cachorros-quentes comercializados em diferentes estabelecimentos de um município localizado na região oeste do estado do Paraná.

\section{METODOLOGIA}

\subsection{COLETA DAS AMOSTRAS}

Foram analisadas 5 amostras de cachorros-quentes, onde cada amostra foi denominada amostra A, B, C, D, E que estavam prontos para o consumo, adquiridas em diferentes estabelecimentos localizados na região Oeste do Estado do Paraná no mês de agosto de 2018, seguindo o protocolo microbiológico do guia de aulas práticas de métodos de análise microbiológica em alimento, que segue as especificações da Resolução RDC no 12 de 02 de janeiro de 2001 da Agência Nacional de Vigilância Sanitária.

As amostras foram coletadas no período noturno e adquiridas na qualidade de consumidor. Imediatamente, após a aquisição, as amostras foram acondicionadas em sacos estéreis de forma asséptica, armazenadas em caixas isotérmicas e refrigeradas para o posterior processamento no laboratório de Microbiologia do Centro Universitário Da Fundação Assis Gurgacz.

\subsection{PREPARO DAS AMOSTRAS}

Com o auxílio de uma faca estéril cada amostra de cachorro-quente foi dividida em três pedaços e pesados. Para auxiliar na diluição das amostras foi utilizado um liquidificador asséptico, no qual foram adicionadas $25 \mathrm{~g}$ da amostra em $225 \mathrm{ml}$ de solução peptonada estéril a $0,1 \%\left(10^{-1}\right)$. Em seguida foram realizadas diluições sucessivas até obter as diluições $10^{-2}$ e $10^{-3}$ (SILVEIRA, et al, 2013).

As amostras foram submetidas a análises para verificação da presença de coliformes totais, Coliformes termotolerantes $\left(45^{\circ} \mathrm{C}\right)$, Staphylococcus spp. coagula-se positiva, mesófilos aeróbios e Salmonella spp.. As análises foram realizadas em triplicata. 


\subsection{COLIFORMES TOTAIS E COLIFORMES TERMOTOLERANTES (45ํ)}

Para a determinação de coliformes totais e termotolerantes, foi transferido $1 \mathrm{ml}$ de cada diluição para tubos contendo caldo lauril-sulfato-triptose (LST), em triplicata, com tubos de Durhan invertidos, e incubados a $35^{\circ} \mathrm{C}$ de 24 a 48 horas. Os tubos que apresentaram turvamento e produção de gás no caldo LST foram considerados positivos.

Para a contagem de coliformes totais transferiu-se uma alçada dos tubos de caldo LST para tubos contendo caldo verde brilhante (VB) com Durhan invertidos e incubados a uma temperatura de $35^{\circ} \mathrm{C}$ por $24 / 48$ horas. Já para a contagem de coliformes termotolerantes transferiu-se uma alçada dos tubos de caldo LST para tubos contendo caldo Escherichia coli (EC) e incubados em banho-maria a $45^{\circ} \mathrm{C}$ por $24 / 48$ horas.

Foram considerados positivos os tubos que apresentaram turvamento $\mathrm{e}$ produção de gás no caldo VB e EC. Com os tubos de EC positivos foram realizados o teste confirmativo, no qual inoculou-se uma alçada de cada tubo em Ágar EMB utilizando a técnica de estria de esgotamento e incubado a $35^{\circ} \mathrm{C}$ por 24 horas.

Posteriormente, nas colônias que não apresentaram centro enegrecido e brilho verde metálico, para confirmação de Escherichia coli foram submetidas à série bioquímica, indol inoculou-se uma alçada em caldo Triptona $1 \%$ incubado a $35^{\circ} \mathrm{C}$ por 24 horas; o teste vermelho metila (VM) foi inoculado uma alçada em caldo VM VP e incubado a uma temperatura de $35^{\circ} \mathrm{C}$ por 96 horas; Teste VogesProskauer (VP) transferiu-se $1 \mathrm{~mL}$ do caldo VM VP para um tubo estéril incubado a $35^{\circ} \mathrm{C}$ por 48 horas; o teste de Citrato inoculou-se uma alçada em Ágar Citrato De Simmons e foi incubado a uma temperatura de $35^{\circ} \mathrm{C}$ por 98 horas.

Após o tempo de incubação, para considerar positividade para Eschericia coli no teste de indol foram adicionadas cinco gotas do Reagente De Kovacs e verificado se houve a formação de um anel de cor vermelha; no teste vermelho metila (VM) foram adicionadas cinco gotas de solução vermelha de metila e verificado se houve alteração na cor do meio (vermelho ou amarelo); teste VogesProskauer (VP) foi adicionado $0,6 \mathrm{~mL}$ de solução de alfa-naftol $5 \%, 0,2 \mathrm{~mL}$ de solução $\mathrm{KOH} 40 \%$, e uma pitada de creatina, verificando se houve ou não alteração na cor do meio; no teste de Citrato analisou-se a cor do meio, verificando se ficou verde ou mudou para a cor azul escuro (SILVEIRA, et al, 2013).

\subsection{Staphylococcus spp. COAGULASE POSITIVA}

Para a determinação de Staphylococcus spp. coagulase positiva, inoculou-se $0,1 \mathrm{~mL}$ de cada diluição na superfície de placas com o ÁgarBaird-Parker (BP), utilizando a técnica de inoculação por espalhamento em superfície em movimentos circulares com o auxílio da alça de Drigalsky e incubado a uma temperatura de $37^{\circ} \mathrm{C}$ por 24/48 horas. As placas foram submetidas a contagem das colônias típicas e atípicas de Staphylococcus spp. e a realização do teste confirmativo.

Para confirmação de Staphylococcus spp. foram escolhidos 5 colônias do micro-organismo, inoculando cada colônia em um tubo contendo caldo $\mathrm{BHI}$ e incubando a uma temperatura de $35^{\circ} \mathrm{C}$ por $18 / 24$ horas, inoculou-se $0,1 \mathrm{ml}$ do caldo $\mathrm{BHI}$ com o micro-organismo em um tubo contendo coagulase plasma incubado em banho maria a uma temperatura de $35^{\circ} \mathrm{C}$ por 6 horas. Por último foi verificado se os tubos apresentaram coagulação (SILVEIRA et al., 2013). 


\subsection{MESÓFILOS AERÓBIOS}

Para a realização da contagem total de micro-organismos Mesófilos, foi adicionado $1 \mathrm{~mL}$ das diluições $\left(10^{-1}, 10^{-2}\right.$ e $\left.10^{-3}\right)$ em uma placa estéril e em seguida adicionado o Ágar Padrão Para Contagem, com o auxílio de uma alça descartável estéril misturou-se o meio junto com o Ágar, realizando movimentos em forma de oito, as placas foram incubadas a uma temperatura de $35^{\circ} \mathrm{C}$ por 48 horas para realização da contagem das colônias de Mesófilos (SILVEIRA et al., 2013).

\subsection{Salmonella spp.}

Para a determinação da presença ou a ausência de Salmonella spp., foi utilizada a diluição $10^{-1} \mathrm{e}$ incubada a $37^{\circ} \mathrm{C}$ por 18 horas, inoculou-se $1 \mathrm{~mL}$ da diluição $10^{-1} \mathrm{em}$ um tubo contendo caldo tetrationado e incubou-se a $37^{\circ} \mathrm{C}$ por 24 horas. Foi inoculado $0,1 \mathrm{~mL}$ da diluição $10^{-1} \mathrm{em}$ um tubo contendo caldo Rappaport e incubado em banho Maria a $41,5^{\circ} \mathrm{C}$ por 24 horas. Posteriormente, foi inoculada uma alçada de cada meio de Tetrationato e Rappaport em Ágar XLD, utilizando a técnica de estria de esgotamento, incubado a $37^{\circ} \mathrm{C}$ por 24 horas, e em Ágar Bismuto Sulfito (BS) a $37^{\circ} \mathrm{C}$ por 24/48 horas.

Para cada placa de XLD e BS foi realizado a série bioquímica, sendo eles: Teste de crescimento em TSI, inoculado com o auxílio de uma agulha de platina o microorganismo presente na placa em Ágar; TSI; Teste de crescimento em LIA, inoculado uma alçada do micro-organismo em caldo lisina ferro; teste de Urease o microorganismo foi inoculado com o auxílio da agulha de platina em Ágar Uréia de Christensen; teste de Voges-Proskauer foi inoculado uma alçada em caldo VM VP; teste de Indol, inoculado uma alçada em caldo Triptona $1 \%$. Todos os testes foram incubados a uma temperatura de $37^{\circ} \mathrm{C}$ por 24 horas.

Os tubos de cada teste foram analisados, sendo que: Teste de crescimento em TSI verificou se houve ou não a alteração na cor do meio (rampa vermelha e fundo amarelo); Teste de crescimento em LIA se houve ou não a alteração da cor do meio (rampa roxa e fundo roxo escuro); Teste de Urease verificou se a cor do meio se tornou rosa escuro, Teste Voges-Proskauer foi adicionado 2 gotas de solução de $\mathrm{KOH}$ $40 \%, 3$ gotas de solução alfa-naftol $5 \%$ e 1 pitada de creatina e verificou se a cor do meio se tornou vermelha. Teste de Indol foi adicionado cinco gotas do Reagente De Kovacs e analisado se houve ou não a formação de um anel vermelho-violeta (SILVEIRA et al., 2013).

\section{RESULTADOS E DISCUSSÃO}

A análise dos resultados foi feita com base na RDC $n^{\circ} 12$, de 2 de janeiro de 2001, a qual define os níveis aceitáveis de micro-organismos para produtos de confeitaria, lanchonetes, padarias e similares, doces e salgados - prontos para 0 consumo humano, da Agência Nacional de Vigilância Sanitária (ANVISA, 2001).

$\mathrm{Na}$ Tabela 1 é possível analisar os resultados obtidos em relação à presença de Staphylococcus spp. Coagula se positiva, Salmonella spp. e a realização da contagem total de micro-organismos Mesófilos.

Ao analisar os resultados verificou-se que $60 \%$ das amostras estavam contaminadas por Salmonella spp., estando em completo desacordo com os critérios determinados pela resolução RDC № 12/2001, que define como ideal a completa ausência desta bactéria nos alimentos. Os resultados deste estudo foram semelhantes aos resultados obtidos por Santos (2015) que também, analisou 
cachorros-quentes comercializados por vendedores ambulantes, onde $100 \%(n=6 / 6)$ das amostras estavam contaminadas por Salmonella spp. tornando os alimentos inadequados para o consumo humano.

Tabela 1. Resultados das análises microbiológicas de amostras de lanches tipo cachorro-quente para a pesquisa de Salmonella spp, Mesófilos aeróbios e Staphylococcus spp. Coagulase Positiva.

\begin{tabular}{cccc}
\hline & $\begin{array}{c}\text { Salmonella spp. } \\
25 \mathrm{~g}\end{array}$ & $\begin{array}{c}\text { Mesófilos aeróbios } \\
\text { UFC/g }\end{array}$ & $\begin{array}{c}\text { Staphylococcus } \\
\text { spp. Coagulase } \\
\text { Positiva } \\
\text { UFC/g }\end{array}$ \\
\hline A & Ausência & $>3$ & Ausência \\
B & Ausência & $>3$ & Ausência \\
C & Presença & $8,1 \times 10^{3}$ & Ausência \\
D & Presença & $1,12 \times 10^{2}$ & Ausência \\
E & Presença & $9,6 \times 10^{4}$ & Ausência \\
\hline
\end{tabular}

*Nota: UFC/g: Unidade Formadora de Colônias por Grama. Limite adotado para Mesófilos aeróbios: $10^{5} \mathrm{UFC} / \mathrm{g}$.

A contaminação por Salmonella spp. possivelmente ocorre, por conta desta bactéria fazer parte da microbiota intestinal das aves e consequentemente estar presente nas suas fezes, sendo que elas são utilizadas como adubo natural para as hortaliças cultivadas nas hortas de pequenos produtores. Além disso, algumas pessoas são portadoras assintomáticas da Salmonella spp., podendo transmiti-la quando não realizada a higienização correta das mãos antes da manipulação destes alimentos. Também pode haver riscos de contaminação cruzada, de outros alimentos em contato com a mesma superfície de preparo (ALBERTI et al., 2014; CASEMIRO E MARTINS, 2016).

A realização da pesquisa de Salmonella spp. é muito importante visto que, mesmo em pequenas quantidades, esta bactéria entérica é a responsável por ocasionar casos graves de septicemia e infecções alimentares, existem vários sorovares de Salmonella spp. e todas possuem algum grau de patogenicidade aos seres humanos (ALBERTI et al., 2014).

As bactérias mesófilas aeróbicas foram confirmadas em $40 \%$ das amostras, estando em discordância com o determinado pela legislação, na qual, segundo Santana, et al (2015) o limite adotado é de $10^{5} \mathrm{UFC} / \mathrm{g}$ ou $\mathrm{ml}$. A RDC no 12/2001, que estabelece os padrões microbiológicos sanitários para alimentos destinados ao consumo humano, não estipula padrões para micro-organismos aeróbios mesófilos.

Os resultados de Gil (2013) foram semelhantes, nos quais, verificou-se que $90 \%(n=18 / 20)$ das amostras obtinham o valor de micro-organismos aeróbios mesófilos acima do permitido, sendo classificadas como "não satisfatórias". A alta contagem de mesófilos aeróbios pode indicar uma situação de risco à saúde pública, devido a uma possível falta de higiene na hora de manipular o alimento, contribuindo para um risco potencial da ocorrência de intoxicações alimentares (SANTOS, 2015).

A contaminação de mesófilos ocorre devido a estas bactérias serem comuns em alimentos crus e artesanais, principalmente quando são produzidos e comercializados em vias públicas, devido à exposição as condições ambientais. Outro fator favorável à contaminação é a falta de higienização e sanitização dos materiais e das mãos do manipulador na hora de produzir o alimento (BECKER et al., 2012). 
Conforme é possível observar, 100\% das amostras analisadas apresentaram ausência para Staphylococcus spp. coagula se positiva, o que deixa os cachorrosquentes de acordo com os limites estabelecidos pela legislação para esse microorganismo. Este estudo obteve os mesmos resultados em comparação aos resultados obtidos por Parissenti et al (2013) no qual não detectaram a contaminação por Staphylococcus spp. em nenhuma amostra analisada $(n=15 / 15)$.

A detecção deste micro-organismo é muito importante, pois sua presença em contagens elevadas indica falta de higiene na manipulação dos alimentos. Além disso, o Staphylococcus spp. é utilizado para confirmar o envolvimento em surtos de intoxicação alimentar e ainda é utilizado como indicador de contaminação pósprocesso ou das condições de sanitização das superfícies que o alimento entrou em contato durante o processamento (ALVES; JARDIM, 2010). A Tabela 2 apresenta os resultados obtidos em relação ao número mais provável de coliformes totais e Termotolerantes.

Tabela 2. Resultados das análises microbiológicas de amostras de lanches tipo cachorro-quente para a pesquisa de coliformes totais e Termotolerantes.

\begin{tabular}{ccc}
\hline \multicolumn{3}{c}{ Coliformes } \\
\hline Totais NMP/g & Termotolerantes NMP/g \\
\hline A & $2,4 \times 10^{3}$ & $<3$ \\
B & $1,1 \times 10^{4}$ & $7,2 \times 10^{1}$ \\
C & $1,1 \times 10^{4}$ & $7,3 \times 10^{1}$ \\
D & $1,1 \times 10^{3}$ & $3,6 \times 10^{1}$ \\
E & $1,1 \times 10^{3}$ & $1,1 \times 10^{3}$ \\
\hline
\end{tabular}

Padrão de contagem de acordo com a RDC n. 12 (Anvisa) de 2 de janeiro de 2001, para produtos de confeitaria, lanchonete, padarias e similares, em que o limite para coliformes Termotolerantes é de até $5 \times 10^{2} \mathrm{NMP} / \mathrm{g}$ ou $\mathrm{ml}$ para coliformes totais a RDC não estabelece padrão máximo.

* Nota: NMP/g: número mais provável por grama.

A legislação atual não estabelece padrões para contagem de Coliformes Totais em lanches prontos para o consumo, devido a isto, foi adotado o mesmo limite que é descrito na RDC № 12 de janeiro de 2001 para Coliformes Termotolerantes e que foi utilizado por Becker et al (2012).

Ao analisar a tabela verificou-se que $100 \%$ das amostras de Coliformes Totais estavam em desacordo com os critérios estabelecidos pela legislação, sendo elas consideradas insatisfatórias. Em estudo similar Becker et al (2014) constatou que 83\% $(n=10 / 12)$ das amostras analisadas estavam em desacordo com os limites estabelecidos. As Contagens elevadas de coliformes totais sugerem que as práticas de higienização e de manipulação na hora de processar os alimentos são realizadas de forma inadequada (SANTANA et al., 2015).

Após analisar os resultados obtidos, identificou-se que $40 \%$ das amostras apresentaram discordância com relação ao limite estabelecido pela legislação que é de $5 \times 10^{2} \mathrm{NMP} / \mathrm{ml}$ para coliformes Termotolerantes. Nos resultados obtidos por Parissenti et al (2013) foi constatado que 100\% ( $n=15 / 15)$ das amostras estavam de acordo com os limites estabelecidos pela RDC no 12/2001, que é de até $5 \times 10^{2} \mathrm{NMP} / \mathrm{g}$ ou $\mathrm{mL}$.

A contagem de coliformes termotolerantes é de extrema importância pelo fato desse ser um micro-organismo de origem exclusivamente fecal, ou seja, este microorganismo faz parte da microbiota intestinal dos seres humanos, consequentemente 
a possível contaminação com coliformes Termotolerantes se dá pela falta da higienização correta das mãos do indivíduo que faz a manipulação do alimento, após utilizar o banheiro (SANTANA et al., 2015).

Devido à fácil transmissão destes micro-organismos, a realização da higienização e sanitização dos materiais e do ambiente no qual será produzido o alimento é de extrema importância, para evitar qualquer possível contaminação aos alimentos que serão servidos ao consumidor final. Também é muito importante a vigilância sanitária monitorar estes estabelecimentos para que eles sempre tomem as devidas precauções na hora de manipular o alimento em questão (MACHADO et al., 2015).

\section{CONCLUSÃO}

Após análise dos resultados é possível concluir que os estabelecimentos correspondentes as amostras A, C, D, E possivelmente não estão realizando as práticas corretas de sanitização e apresentam riscos de uma possível intoxicação à população que consome os alimentos servidos nestes locais.

\section{REFERÊNCIAS}

ALBERTI, J.; CASTANHA, S. F.; NAVA, A. Avaliação Microbiológica De CachorrosQuentes Comercializados Por Ambulantes No Município De Xanxerê, Sc.

Rev.Unoesc\& Ciência - ACBS - Edição Especial, p. 41-46, 2014. Disponível em: <http://editora.unoesc.edu.br/index.php/acbs/article/view/4346> Acessado em: 07. OUT. 2018.

ALVES, P. T.; JARDIM, F. B. B. Análise microbiológica de cachorros-quentes comercializados na cidade de Uberaba, MG. Cadernos de Pós-Graduação da FAZU, $\quad v . \quad 2010.20$ Disponível <http://www.fazu.br/ojs/index.php/posfazu/article/view/341> Acessado em: 27. SET. 2018.

ANDRADE, N. J. REVISTA HIGIENE ALIMENTAR. Higiene na indústria de alimentos. Ed. 664.07, São Paulo, Varela, 2008.

ANVISA - AGÊNCIA NACIONAL DE VIGILÂNCIA SANITÁRIA. Resolução RDC no12, de 02 de janeiro de 2001. Disponível em: <http://portal.anvisa.gov.br/Acessado em: 15. AGO. 2018.

BECKER, G. A.; MACHADO, L. M.; KMIECIK, J.; DELLER, J.; SOUZA, C. M.; ISAKA, G. V. Qualidade higiênico-sanitária de cachorros-quentes comercializados em pontos de venda informais de alimentos em Canoinhas-SC. $4^{\circ}$ Seminário de Pesquisa, Extensão e Inovação do IFSC, Santa Catarina, 2014. Disponível em: <file:///C:/Users/HIORANA/Downloads/639-3564-1-PB.pdf> Acessado em: 06. OUT. 2018.

CARVALHO, M. S. M.; ANDRADE, D. F. R.; SOUSA, A. F. L.; VALLE, A. R. M. C.; FREITAS, D. R. J.; NASCIMENTO, G. C.; ANDRADE, D.; WATANABE, E. Colonização nasal por Staphylococcus aureus entre estudantes de Enfermagem: subsídios para monitorização. Rev. Bras. Enferm. 69(6):1046-51, 
2016. Disponível em: <http://www.scielo.br/pdf/reben/v69n6/0034-7167-reben-69-061046.pdf> Acessado em: 04. ABR. 2018.

CARVALHO, I.T. e-TEC BRASIL. Técnico em Alimentos. 2010. Disponível em: <http://redeetec.mec.gov.br/images/stories/pdf/eixo_prod_alim/tec_alim/181012_micr o_alim.pdf> Acessado em: 28. SET. 2017.

CASEMIRO, L. P.; MARTINS, A. L. O. Prevalência de contaminação microbiológica e parasitológica de maioneses caseiras comercializadas em carrinhos de cachorro-quente. Universidade do Sul de Santa Catarina. Tubarão, SC, 2016. Disponível em: <http://www.rbac.org.br/artigos/prevalencia-decontaminacao-microbiologica-e-parasitologica-de-maioneses-caseiras-

comercializadas-em-carrinhos-de-cachorro-quente/> Acessado em: 14. OUT. 2018.

EVANGELISTA, J. Tecnologia de Alimentos. 2ed. São Paulo, Rio de Janeiro, Ribeirão Preto, Belo Horizonte. Atheneu, 2008.

FERREIRA, H.; LIMA, H.; COELHO, T. Microrganismos indicadores em alimentos de origem animal. Universidade Federal Rural do Semiárido, 2014. Disponível em: <http://www2.ufersa.edu.br/portal/view/uploads/setores/126/Resumo\%20MO\%20indi cadores.\%20Heider,\%20Hiagos,\%20Thiago.pdf> Acessado em: 04. ABR. 2018.

GIL, J. F. L. Avaliação da qualidade microbiológica de produtos alimentares comercializados em unidades móveis (Roulottes) do grande Porto. U.Porto, 2013. Disponível em: <file:///C:/Users/HIORANA/Downloads/Tese_Joana_Gil.pdf> Acessado em: 06. OUT. 2018.

LIMA, I. A.; GEUS, J. A. M. Análisede coliformes totais e fecais: um comparativo entre técnicas oficiais vrba e petrifilmec aplicados em uma indústria de carnes. 2008. Disponível em: <http://www.pg.utfpr.edu.br/ppgep/anais/artigos/eng_tec_alimentos/12\%20ANALISE \%20DE\%20COLIFORMES\%20TOT\%20FECA\%20UM\%20COMPAR\%20TEC\%200 FIC\%20VRBA\%20PE.pdf> Acessado em: 03. OUT. 2017.

MACHADO, R. L. P.; DUTRA, A. S.; PINTO, M. S. V. Boas Práticas de Fabricação (bpf). Embrapa. 23ed. Rio de Janeiro, 2015. Disponível em: <https://ainfo.cnptia.embrapa.br/digital/bitstream/item/132846/1/DOC-120.pdf> Acessado em: 03. OUT. 2017.

MINISTÉRIO DA SAÚDE (MS). Manual Integrado de Vigilância, Prevenção e Controle de Doenças Transmitidas por Alimentos. Editora MS, Brasília, DF, 2010. Disponível em: <http://bvsms.saude.gov.br/bvs/publicacoes/manual_integrado_vigilancia_doencas_ alimentos.pdf> Acessado em: 20. SET. 2018.

OLIVEIRA, A. B. A.; PAULA, C. M. D.; CAPALONGA, R.; CARDOSO, M. R. I.; TONDO, E. C. Doenças transmitidas por alimentos, principais agentes etiológicos e aspectos gerais: uma revisão. Rev. HCPA; 30(3), Porto Alegre, RS, 2010. 
$<$ https://www.lume.ufrgs.br/bitstream/handle/10183/157808/000837055.pdf?sequenc e=1> Acessado em: 20. SET. 2018.

PARISSENTI, A. C.; ROVEDA, B. L. G.; SALMORIA, L. C.; SANTIN, N. C. Avaliação Microbiológica de Cachorros-Quentes Comercializados por Vendedores Ambulantes na Cidade de Videira, SC. Unoesc \& Ciência v.4, p. 91-100, 2013. Disponível em: <https://editora.unoesc.edu.br/index.php/acbs/article/download/2536/pdf>Acessado em: 01. OUT. 2018.

SANTANA, F. A.; VIEIRA, M. C.; PINTO, U. M. Qualidade microbiológica de sanduíches de estabelecimentos com serviço tipo delivery. Revista Instituto Adolfo Lutz, São Paulo, 2015. Disponível em: <http://www.ial.sp.gov.br/resources/insituto-adolfolutz/publicacoes/rial/rial74_2_completa/pdf/artigosseparados/1650.pdf> Acessado em: 05. OUT. 2018.

SANTOS, L. L. P. Análise Bacteriana de Cachorro Quente de Ambulantes. 15ำ Congresso Nacional de Iniciação Científica SEMESP, Ribeirão Preto - SP, 2015. Disponível em: <http://conic-semesp.org.br/anais/files/2015/trabalho1000019614.pdf > Acessado em: 27. SET. 2018.

SIVEIRA, N. F. A.; OKAZAKI, M. M.; NASCIMENTO M. S.; GOMES, R. A. R.; JUNQUEIRA, V. C. A. Guia de aulas práticas de métodos de análise microbiológica em alimentos. Instituto de tecnologia de alimentos. São Paulo, 2013. 